\title{
Giant thymoma successfully resected via anterolateral thoracotomy: a case report
}

\author{
Takahiro Saito', Takashi Makino', Yoshinobu Hata'', Satoshi Koezuka', Hajime Otsuka', Kazutoshi Isobe², \\ Naobumi Tochigi ${ }^{3}$, Kazutoshi Shibuya ${ }^{3}$, Sakae Homma ${ }^{2}$ and Akira Iyoda ${ }^{1 *}$
}

\begin{abstract}
The appropriate surgical approach for a large mediastinal tumor is controversial. Median sternotomy is the standard approach for thymomas. We herein report the case of a giant thymoma, $13 \mathrm{~cm}$ in diameter, surgically resected via anterolateral incision. Subsequent thymectomy was performed via thoracoscopy. The resected specimen was a WHO type AB thymoma, Masaoka stage I, without capsular invasion. The anterolateral incision was less invasive and more versatile in the present case, as the incision could be extended to a hemiclamshell or posterolateral incision depending on exposure and relationship to adjacent organs and vascular structures.
\end{abstract}

Keywords: Surgery, Giant thymoma, Thymoma, Anterolateral incision

\section{Background}

Thymomas are rare neoplasms with an indolent growth pattern and present with various clinical symptoms [1]. They are commonly found in the anterior mediastinum. Complete surgical resection is the mainstay of treatment. While median sternotomy has been the standard approach for thymectomy, the best incision is controversial for so-called giant thymomas [2]. Here we report the case of a giant thymoma in the anterior-inferior mediastinum successfully resected with additional thymectomy via anterolateral thoracotomy.

\section{Case presentation}

A 45-year-old man was referred to our hospital due to a routine chest $x$-ray showing an abnormal shadow in the right lower lung field (Fig. 1). He had no obvious symptoms, except for slight dyspnea on exertion for three months. He had no smoking history and no significant medical history. No previous chest $\mathrm{x}$-rays were available. Chest CT-scan showed a well-defined mass $13 \times 10 \mathrm{~cm}$ in diameter, in contact with the diaphragm, pericardium, right inferior pulmonary vein, and superior vena cava (Fig. 1). The tumor showed heterogenous contrast effect. F18-fluorodeoxyglucose positron emission tomography (FDG-PET) showed abnormal FDG uptake with maximum

\footnotetext{
* Correspondence: aiyoda@med.toho-u.ac.jp

'Division of Chest Surgery, Toho University School of Medicine, Tokyo, Japan Full list of author information is available at the end of the article
}

standardized uptake value of 4.2. Laboratory examination showed normal serum levels of alpha fetoprotein $(2.4 \mathrm{ng} /$ $\mathrm{ml})$, human chorionic gonadotropin beta $(<0.2 \mathrm{ng} / \mathrm{ml})$ and anti-acetylcholine receptor antibody. Differential diagnosis included thymoma, thymic carcinoma, and a germ cell tumor; surgical resection was thus recommended. Preoperative needle biopsy was not performed because of the risk of dissemination or bleeding. As the tumor showed possible invasion into the superior vena cava, inferior pulmonary vein and diaphragm, we elected to perform an anterolateral thoracotomy in the fifth intercostal space in the semi-lateral decubitus position, which could be extended to a posterolateral thoracotomy or hemi-clamshell thoracotomy depending on the relationship of the tumor to the inferior pulmonary vein or superior vena cava, respectively.

Thoracoscopic examination through the eighth intercostal space revealed no adhesions or pleural disease. An anterolateral incision, $20 \mathrm{~cm}$ in length, was made in the fifth intercostal space. The tumor was excised from the anterior mediastinal fat tissue and thymus. Dense adhesions of the tumor to the pericardium were sharply peeled off, and the tumor was resected without involvement of the superior vena cava or inferior pulmonary vein. Intraoperative frozen section diagnosed the tumor as a thymoma; thymectomy was thus performed through the same incision via thoracoscopy. The adherent portion of the pericardium was excised and reconstructed with the use of a Gore-Tex pericardial patch. 


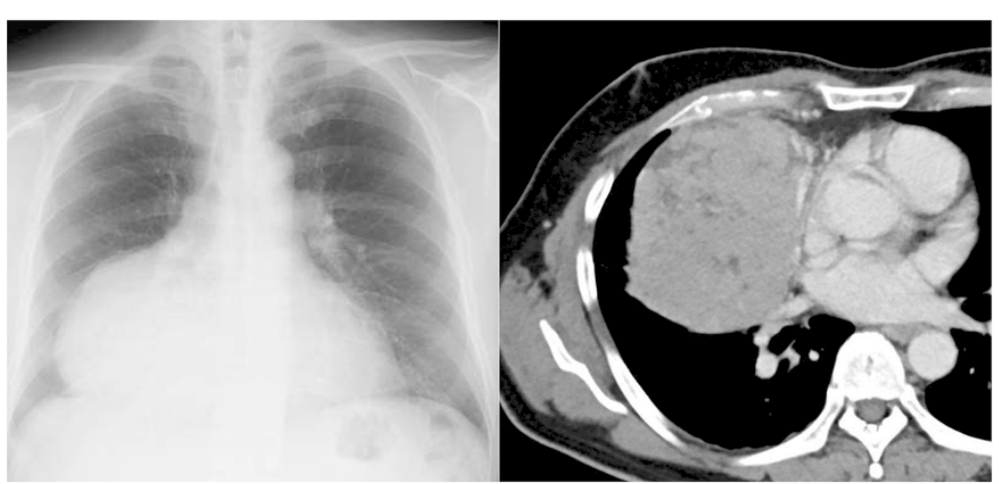

Fig. 1 Chest $x$-ray shows a giant mass in the right lower lung field (left). Chest CT shows a mass measuring 13 x $10 \mathrm{~cm}$ in diameter, in contact with the right inferior pulmonary vein (right)

The resected specimen was $13 \times 11.8 \times 8 \mathrm{~cm}$, showing a well encapsulated tumor with a lobulated appearance separated by fibrous bands. Microscopic examination revealed the tumor to be composed of a lymphocyteassociated area and a spindle cell-dominant area (Fig. 2), which was diagnosed as World Health Organization (WHO) Type AB thymoma without capsular invasion (Masaoka stage I). The postoperative course was uneventful and the patient is free of recurrence 12 months after the surgery.

\section{Discussion}

The optimal surgical approach for giant thymomas is a point of controversy (Table 1). Two cases of giant thymoma resected via anterolateral thoracotomy have been reported [2, 3]. One case was an ectopic pleural thymoma measuring $20 \mathrm{~cm}$ in size located in the lower portion of the right thoracic cavity, with adhesions to the pulmonary pleura of the right lower lobe and central part of the diaphragm [3]. The other case was an anterioinferior mass weighing $1705 \mathrm{~g}$, which was attached to the

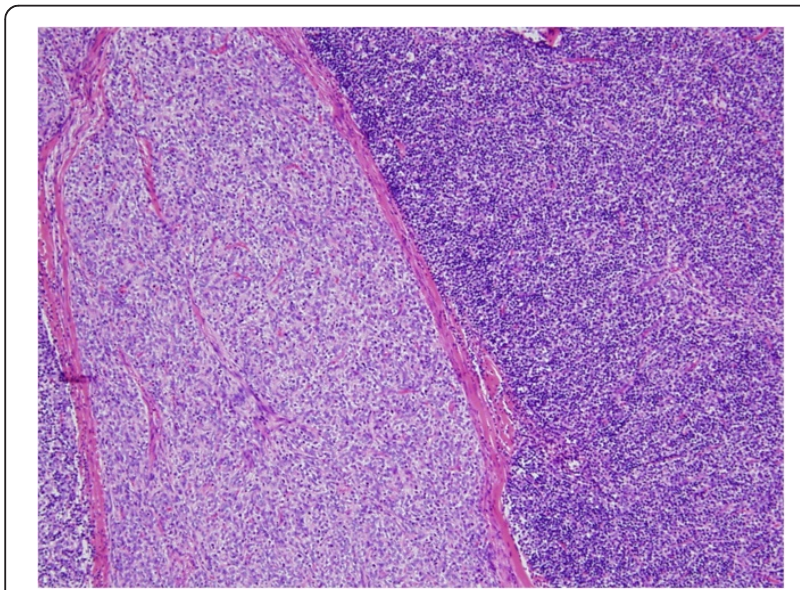

Fig. 2 Microscopic examination revealed a WHO type AB thymoma, without capsular invasion mediastinal pleura via a small vascular bundle. This was easily removed after transection of the pedicle, and additional thymectomy was performed [2]. In the present case, we preferred the anterolateral approach because the incision could be extended to either a posterolateral approach in the case of adhesions to the inferior pulmonary vein, or a hemiclamshell approach in case of adhesions to the superior vena cava. Additional thymectomy was successfully performed via the same incision via thoracoscopy, thus avoiding the need for a second operation.

While median sternotomy is the standard approach for thymomas, only three cases of giant thymomas resected via median sternotomy have been reported [4-6]. Median sternotomy was suitable for one case with invasion into the innominate vein [4], but access to the hilum [7] or posterior thorax can be difficult in cases of giant thymomas. A hemiclamshell approach is a reasonable approach for giant thymomas [2], but is relatively more invasive compared with the other approaches. The clamshell incision, widely used in lung transplantation procedures, was selected in an emergency operation for a patient in shock secondary to spontaneous rupture of a giant thymoma, thought to be a giant sarcoma in close contact with the pulmonary artery [7]. The clamshell approach enables rapid tumor control and easy access to the hilum. A posterolateral approach was reported in two cases $[8,9]$. One case was an ectopic pleural thymoma, preoperatively suspected to be a solitary fibrous tumor, and a subsequent transcervical thymectomy was not performed. In the other case, the remaining thymus gland portions were removed through a median sternotomy at a second operation [9]. Anterolateral thoracotomy is less invasive than the clamshell and hemiclamshell approaches, and may be appropriate for cases of giant thymoma.

While the size of the thymoma has been reported to be a significant prognostic factor from experienced single centers $[10,11]$, sporadic case reports of giant thymomas larger than $13 \mathrm{~cm}$ consisted of 4 cases of WHO 
Table 1 Surgical approach for giant thymoma

\begin{tabular}{|c|c|c|c|}
\hline Approach & $n$ & Cases & Remarks \\
\hline \multirow[t]{2}{*}{ Median sternotomy [reference 4-6] } & \multirow[t]{2}{*}{3} & \multirow[t]{2}{*}{ Anterior masses } & Suitable for invasion into innominate vein \\
\hline & & & Possible blind spot caused by anterior mass \\
\hline \multirow[t]{2}{*}{ Hemiclamshell [reference 12-14] } & \multirow[t]{2}{*}{3} & \multirow{2}{*}{$\begin{array}{l}\text { Large masses occupying more than half of } \\
\text { thorax }\end{array}$} & Easy access to the mediastinum and hilum \\
\hline & & & Relatively invasive \\
\hline \multirow[t]{3}{*}{ Posterolateral [reference 8, 9] } & \multirow[t]{3}{*}{2} & \multirow[t]{3}{*}{ Masses close to the diaphragm } & Suitable for inferior mediastinal masses \\
\hline & & & Requires thymectomy at second operation \\
\hline & & & Unsuitable for antero-superior mediastinal masses \\
\hline \multirow[t]{2}{*}{ Anterolateral [reference 2, 3] } & \multirow[t]{2}{*}{2} & Antero-inferior masses & $\begin{array}{l}\text { Possible to extend the incision posteriorly or with median } \\
\text { sternotomy }\end{array}$ \\
\hline & & Ectopic mass & Unsuitable in cases that are unstable in the decubitus position \\
\hline \multirow[t]{2}{*}{ Clamshell [reference 7] } & \multirow[t]{2}{*}{1} & \multirow[t]{2}{*}{ Masses with bleeding } & Quick access to the hilum and tumor control \\
\hline & & & Invasive \\
\hline
\end{tabular}

type A, 6 cases of type $A B$ (including the present case), and 2 cases of type B1 [2-9, 12-14]. Although the five year survival for thymomas more than $10 \mathrm{~cm}$ is reported to be $72 \%$ [10], successfully resected giant thymomas tend to be low-grade [12].

\section{Conclusion}

In the present case, surgical resection for a giant thymoma and additional thymectomy were successfully performed via an anterolateral approach, which is relatively less invasive and more versatile due to the ability to extend the incision posteriorly or to add a median sternotomy.

\section{Consent}

Written informed consent was obtained from the patient for publication of this case report and any accompanying images. A copy of the written consent is available for review by the Editor-in-Chief of this journal.

\section{Abbreviations}

FDG-PET: F18-fluorodeoxyglucose positron emission tomography; WHO: World Health Organization.

\section{Competing interests}

The authors declare that they have no competing interests.

\section{Authors' contributions}

All authors participated in the design of the case report and helped to draft the manuscript. All authors read and approved the final manuscript.

\section{Acknowledgements}

This study was supported in part by a Grant-in-aid for Scientific Research (C) 15 K10272 from the Japanese Ministry of Education, Culture, Sports, Science and Technology and The Research Promotion Grant from Toho University Graduate School of Medicine (No.15-02 to A.I.).

\section{Disclosures}

The authors have no funding, no financial relationships, and no conflicts of interests.

\section{Author details}

${ }^{1}$ Division of Chest Surgery, Toho University School of Medicine, Tokyo, Japan. 2Division of Respiratory Medicine, Toho University School of Medicine, Tokyo, Japan. ${ }^{3}$ Department of Surgical Pathology, Toho University School of Medicine, Tokyo, Japan.

Received: 6 June 2015 Accepted: 24 August 2015

Published online: 01 September 2015

\section{References}

1. Falkson CB, Bezjak A, Darling G, Gregg R, Malthaner R, Maziak DE, et al. The management of thymoma: a systematic review and practice guideline. J Thorac Oncol. 2009:4:911-9.

2. Limmer S, Merz H, Kujath P. Giant thymoma in the anterior-inferior mediastinum. Interact Cardiovasc Thorac Surg. 2010:10:451-3.

3. Yamazaki K, Yoshino I, Oba T, Yohena T, Kameyama T, Tagawa T, et al. Ectopic pleural thymoma presenting as a giant mass in the thoracic cavity. Ann Thorac Surg. 2007:83:315-7.

4. Fazlıoğulları O, Atalan N, Gürer O, Akgün S, Arsan S. Cardiac tamponade from a giant thymoma: case report. J Cardiothorac Surg. 2012;7:14.

5. Spartalis ED, Karatzas T, Konofaos P, Karagkiouzis G, Kouraklis G, Tomos P. Unique presentation of a giant mediastinal tumor as kyphosis: a case report. J Med Case Rep. 2012;6:99.

6. Sim EK, Lee CN, Mestres CA, Adebo OA. Ectopic thymoma: a case for median sternotomy for complete thymectomy. Singapore Med J. 1992;33:407-8.

7. Santoprete S, Ragusa M, Urbani M, Puma F. Shock induced by spontaneous rupture of a giant thymoma. Ann Thorac Surg. 2007;83:1526-8.

8. Filosso PL, Delsedime L, Cristofori RC, Sandri A. Ectopic pleural thymoma mimicking a giant solitary fibrous tumour of the pleura. Interact Cardiovasc Thorac Surg. 2012;15:930-2.

9. Gotte JM, Bilfinger TV. Resection of giant right-sided thymoma using a lateral thoracotomy approach followed by median sternotomy for completion thymectomy. Thorac Cardiovasc Surg. 2007:55:336-8.

10. Nakagawa $\mathrm{K}$, Asamura $\mathrm{H}$, Matsuno $\mathrm{Y}$, Suzuki $\mathrm{K}$, Kondo $\mathrm{H}$, Maeshima A, et al. Thymoma: a clinicopathologic study based on the new World Health Organization classification. J Thorac Cardiovasc Surg. 2003;126:1134-40.

11. Wright CD, Wain JC, Wong DR, Donahue DM, Gaissert HA, Grillo HC, et al. Predictors of recurrence in thymic tumors: importance of invasion, World Health Organization histology, and size. J Thorac Cardiovasc Surg. 2005;130:1413-21.

12. Takenaka T, Ishida T, Handa Y, Tsutsui S, Matsuda H. Ectopic thymoma presenting as a giant intrathoracic mass: a case report. J Cardiothorac Surg 2012;7:68.

13. Takanami I, Takeuchi K, Naruke M. Noninvasive large thymoma with a natural history of twenty-one years. J Thorac Cardiovasc Surg. 1999;118:1134-5

14. Tsubota N, Murotani A, Yoshimura M. A huge non-invasive thymoma causing acute dyspnea. Tohoku J Exp Med. 1993;171:229-33. 